\title{
Motivations in the Sharing Economy: A Study of Profit and Non-profit Services in the Tourism Context
}

\author{
Greicy K Silva \\ Faculty of Sciences \\ \& Technology (UNL) \\ Lisbon, 2267057, Portugal \\ greicy.silva@m-iti.org
}

\author{
Claudia Silva \\ Madeira Interactive \\ Technologies Institute \\ Funchal, 2267057, Portugal \\ claudia.silva@m-iti.org
}

\begin{abstract}
This paper reports on a study of motivations for the use of product service system category in the sharing economy. We interviewed service providers of these systems, profit and non-profit in the tourism context, to obtain different perspectives and to determine if providers are matching their system designs to the drivers of the new economy. We found that the motives implicit in providers' explanations of their systems' designs experience are extremely positive and reliable. Providers interviewed do not place emphasis on intrinsic motivations such as environmental sustainability. We discuss the divergent provider's motives and will suggest future work implications for the design for collaborative economy community.
\end{abstract}

The sharing economy. Motivation theory. Service provider.

\section{INTRODUCTION}

In most cases, the two common characteristics in the variety of online platforms in the new economy are: the technology support to distribute power to users and the efficient utilization of assets [5]. It has been argued that by promoting sharing, reuse and sustainability will prevent climate change by its new way of consumption [5,14]. Former authors say that people are consuming motivated by economic and institutional reasons not by awareness and concerns around environmental decisions for the present and future generations $[14,7]$. The consumer literature has affirmed that sharing is closely related to trust [1]. Still, in the context of business, pioneer authors have described how trust relates to the crucial role in the sharing economy and have referred to it as currency [4]. While the sharing economy has been explored from different views and fields, however, this phenomenon remains challenging in part for its interdisciplinary characteristic.

eMarketer $^{1}$ (2017) estimated that sharing economy users will increase in 30\% in the US until 2021. In meanwhile, Airbnb in the capital of Portugal has been had a rental growth of $42 \%$ per year where $73 \%$ of hosts have more than one property listed on

\footnotetext{
${ }^{1}$ Retrieved February 20, 2018 from

https://www.emarketer.com/Article/Uber-Airbnb-Lead-Way-SharingEconomy-Expands/1016109
}

the platform ${ }^{2}$. Though Airbnb has been growing success since it started back in 2008 , the company has also accumulated a number of discredited activities involving robbery, property damages in hosts' properties, and faced issues with taxes and regulations. Further, the rise of the sharing economy claims results in reducing energy and water use and encourages sustainable practices among hosts and guests. For instance, a potential change in user needs patterns on this technological phenomenon may have a significant impact to examine the role and effect of users' motivation to use product service system platforms in the tourism context.

In this work, we focus on exploring users motivations aspects of their experiences by delimitating: A) two specific systems in the category of PSS (Product Service System), 1) Airbnb and 2) Couchsurfing. The former is monetized while the last is nonmonetized, B) a local context, in here the tourism set, and C) the motivation theory, that is selfdetermination theory, this theory inspired by two different sources: 1) self-determination theory (classification of motivations into intrinsic and extrinsic motivations) [9,17]; and (2) context-specific adjustments in the study of people's motivation to participate in the sharing economy (participation is motivated by its sustainability, enjoyment, and

\footnotetext{
2 Retrieved February 25, 2018 from https://www.airdna.co/marketdata/app/pt/lisboa/lisbon/overview
} 
reputation of the activity as well as economic gains) [16]. Having these factors in mind, we are questioning how do motivations to use sharing economy services influences use intentions and attitude formation toward the sharing economy?

\section{RELATED WORK}

Previous work on exploring peoples' motivation to participate in the sharing economy has addressed this matter with the divergent models of providers and users to determine if providers are matching their system designs to the drivers of use [2]. This paper [2] applied four different types of motivation theories to a study with people recruited through various online means with four different categories of services, but the breach we identified in here, is due to the generalist approach used in trying to understand what users deeply want and from different contexts, by performing voice-interviews online, meaning not being able to watch the participants reactions in their own environment.

The four principles of the sharing economy contribute to the success of the phenomenon. According to Botsman and Rogers, these guidelines include: trust between strangers, idling capacity, critical mass, and belief in the commons [5]. Each item is uniformly subjective but depending on what is being shared and who is participating in the sharing, some principles may be more critical than others. Many platforms systems of the sharing economy require certain trust between strangers to work. For example, sharing your home requires some level of trust that the individual, in this case, the guest, will not destroy the accommodation. While in the past, these types of exchanges were conducted by a third party, now socio-technical platforms exist to support these interactions.

This phenomenon positions trust as the "new currency" of this new economy, as trust and trustworthiness are considered "drivers of a transaction between strangers" [3]. Inherent in these transactions are several situations of "risk and uncertainty" for the user, because these exchanges are occurring between human - to human, and from online to offline process mediated by technology.

Technological developments are associated with increased complexity [24], and also complemented with risk and uncertainty, because "valuable assets constitute a risk in an interaction; the numerous sources of ambiguity about an outcome create uncertainty" [8]. In each type of interaction, risk and uncertainties may complicate our decisions.

We have been exploring two online platforms, Airbnb and Couchsurfing, defined by itself as part of the sharing economy, adding it to this paper the context of tourism. In fact, tourism is one of the affected areas by peer-to-peer (P2P) service providers that share homes, cars, tours, and meals with tourists. Nevertheless, "researchers in tourism have paid little attention to the impact of this relatively new phenomenon on the tourism landscape" [15].

Taking this fact into account, we collected our dataset from a touristic island. The geographic context is Madeira Island in Portugal, which the tourism sector represented $25 \%$ of the gross domestic product (GDP) in $2016^{3}$.

\subsection{Motivation theory}

The self-determination theory (SDT) says that a person does an activity because finds it rewarding. Inspired by the aspects of the sharing economy, such as enjoyment, economic incentive, reputation, and self-fulfilment [16], we are questioning people's motivation, to start and to continue using and trusting PSS in the sharing economy. These aspects are driving online activities and collaboration [16]. This is like social sharing, an online marketplace that is also motivated by enjoyment, economic benefits, reputation, and collaboration. Reputation and economic interest in 'sharing economy' are mainly stimulating by ideology, such as sustainability and sustainable consumer behaviour.

The motivation theory used to conduct this study comes from SDT [9]. The motivation can be intrinsic, related to the given activity, or extrinsic related to external forces, e.g. collaboration activities in communities. The former comes from the intrinsic value or enjoyment, while the other emerges from reputation and monetization. Another lens we adopted says that exist two types of intrinsic motivations: enjoyment derived from the activity itself and value derived from acting conforming to rules [17] - e.g. having an ecologically sustainable behaviour concerning decisions for the present and future generations.

The results from a study published in 2015 [16] show that participation in the context of sharing economy is motivated by many factors such as sustainability, enjoyment of the activity as well as economic gains. We are using these factors to guide our study.

In this phenomenon, people may perceive an activity positively, and say good things about it, but this good attitude does not necessarily translate into action [16]. Communities and services, in the context of 'collaborative consumption', are generally characterized as driven by the obligation to do good for other people and for the

\footnotetext{
3 Retrieved January 30, 2018 from

http://www.jornaldenegocios.pt/empresas/turismo---lazer/detalhe/ilha-damadeira-premiada-melhor-destino-insular-do-mundo-nos-wta.
} 
environment, such as sharing, helping others, and engaging in sustainable behaviour [18]. However, 'sharing economy' may also incite more individualistic reasons for participating, because it also provides economic benefits.

\section{THE STUDY}

To support our in-depth understanding, we applied qualitative research by collecting data from interviews.

We conducted six open-ended interviews in the Portuguese language with three Airbnb and three Couchsurfing hosts. The time spent was between 30 and 40 minutes each conversation. These users were located on a Portuguese island. Our participants were selected through the two platforms profiles that appeared on the top of the list searched in this geographical area. The responses were gathered in February 2017. Participants were invited to be part of this case study and they agreed to contribute voluntarily to it. They were all active users of the online platforms for more than a year. They were questioned around the participation motivated by intrinsic (enjoyment and sustainability) and extrinsic motivations (reputation and monetization) to have started and to continue to participate in the platform services as a user provider. The questions were designed to help us to capture the users' providers reflexions and impressions. Samples questions included: Can you describe a situation you encountered when you started using a platform? How would you present this platform to other people with the intention that they start using it? Do you consider that your attitudes remain the same as in the beginning? What has changed?

We identified, analysed and coded the interviews using the method of "thematic analysis". The method flexibility allows strong detailed and complex description of the data [6]. We started with generated initial codes related to the question and it supported the creation and identification of themes related to the topic of this paper.

\subsection{Use intensions \& attitude formation}

Our findings and conclusions based on qualitative interview show: individuals' motivation for using Airbnb (profit) and Couchsurfing (non-profit) platforms are different, and sometimes, the use intentions at the beginning of use the system may change according to attitude formation, their own or others' attitude.

The economic gain, an extrinsic motivation, it was the first reason that engages Airbnb usage. But contra pointing this extrinsic reason, the same participants claimed that this platform does not support the creation of a network community inside the platform, a concern related to intrinsic motives of participation. On the other hand, interviews about Couchsurfing users show that the top reason for individuals to host is, to experiencing others' culture without traveling, it means the intrinsic motivations are stronger at a non-profit service system, as expected.

However, it was quite intriguing to find that popular platforms in the realm of "trusted community", such as Couchsurfing, are failing to benefit the common good, as a few hosts were feeling demotivated to continue using the service and considering to migrating to Airbnb. The demotivation is associated with expectation as being the reason. An interviewee stated that she is not getting back the collaboration expected from this platform community. Even though, all participants connected Couchsurfing as being a sharing economy company, not Airbnb.

After reviewing our interview transcripts and linked to the motivations, and the literature in the sharing economy, our data coding framed the following connections (see Figure 1).

\subsubsection{Motivation categories}

To represent the finds in Figure 1, motivations were grouped into categories. For intrinsic motivation are (enjoyment and sustainability), and extrinsic motivation englobes (reputation and monetization). This groups matched to both platform services and the use intentions - started to use the platform services - to attitude formation - related to continued use, or not, of the platform service. After this, we identified the need of separating the two situations of usage, because a previous study in the sharing economy reported the attitude gap that exists between what people say they do and what they actually do [16]. As an attitude refers to emotions, beliefs, and behaviour toward something or someone.

We found the responses, that sometimes intentions of use at the service adoption differs from the continued use of it, which participants said to be the effect of experiences with the platform peers. An example of it, is Couchsurfing as a non-profit platform, is expected to attend more intrinsic intentions on attitudes toward belief in the commons, it is related to balanced reciprocity [10], but as we could verify at the data set, once trust is compromised, this reciprocity is put in doubt.

As Juliet Schor pointed out in 'Debating the Sharing Economy' in 2010, staying in existing homes might reduce the demand to build new hotels [13].

However, to analyse the overall ecological impact, it might be worth asking whether hosts and tourists do not use the money earned or saved to buy more products or to travel more. 


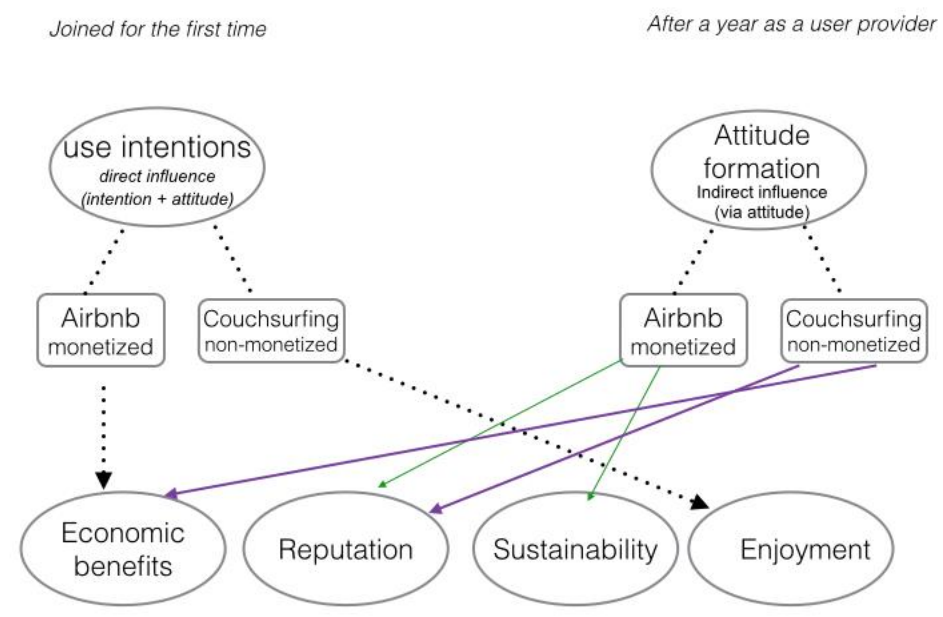

Figure 1: The motivations categories and the platform services connections

This states an attitude formation expected from the consumer's behaviour in today's sharing economy.

Sustainability as an attitude, is another point that took our attention during the study, and this was due to a comment about the local municipality regulation, which all user providers follow with no exception, and also by the comment, made from only one person, who pointed that "there is no need to build more hotels in a small island". This attitude is also considered one of the issues that the new economy promises to solve, through the changes in attitudes toward consumption ant its' concerns over ecological, societal, and developmental impact $[1,4]$. Recently, a systematic review reported a lack of studies in that manner "despite most sharing economy platforms' advertising supposed environmental benefits [11]". Another research work also pointed a lack of studies related to sustainable $\mathrm{HCl}^{4}$. This last topic is one of the attitudes listed in table 1.

\section{CONCLUSION}

Attitude toward in particular thing, situation or person is often the result of their own experience that can have a powerful influence on the intention of use. The sharing economy principles expected to incentive these good behaviours on users. We believe that users experiences' over time added to the sharing economy set of models with purpose may increase the awareness of use. We notice that sometimes existing attitudes demotivates participation, as an example in this research study, the expectations that people deposit on others' actions. This belief we notice to be more relevant

\footnotetext{
${ }^{4}$ Research MSc in Sustainable Development - Pieter_van_de_Glind_bereidheid_tot_delen.pdf. Retrieved February 25, 2018 from https://s3.amazonaws.com/academia.edu.documents/
}

among participants comparing to the imperative trust that they unaware deposited in the relationship with the PSS platforms.

It is a qualitative interview-based study that allows us to compare experiences from users' providers of services in the monetized and non-monetized product service system platforms, specific in the tourism context. The interview was theory-based with the intention to understand peoples' motivation to adopt, to trust, and to continue using Airbnb and Couchsurfing in the touristic Portuguese island, Madeira.

Despite the decrease of publications since 2015 [11], it appears that the sharing economy is going to continue its journey. The sharing economy has transformed many aspects of the tourism sector. In fact, tourism is one of the most affected areas by peer-to-peer sharing as local residents share homes, cars, tours, and meals with tourists [15]. Nevertheless, researchers in tourism have paid little attention to the impact of this relatively new phenomenon on the tourism landscape [12].

\section{FUTURE WORK}

The recent literature review in the sharing economy focused on computing studies had shown that qualitative studies at ACM library are published at a large scale compared to quantitative, mixed methods and design approaches [11]. We aim to further understand local users' motivations in the large context of sharing economy in tourism destinations by undertaking further interviews and observations techniques in the $\mathrm{HCl}$ field. We also want to conduct a number of participatory design sessions for stakeholders in the same context. 


\section{ACKNOWLEDGMENTS}

Acknowledgments to ARDITI - Regional Agency for the Development of Research Technology and Innovation through the support granted under the Project M1420 - 09-5369-FSE-000001- Ph.D. Scholarship.

\section{REFERENCES}

1. Russell Belk. 2010. Sharing. Journal of Consumer Research 36, 5: 715-734.

2. Victoria Bellotti, Alexander Ambard, Daniel Turner, Christina Gossmann, Kamila Demkova, and John M. Carroll. 2015. A Muddle of Models of Motivation for Using Peer-to-Peer Economy Systems. Proceedings of the 33rd Annual ACM Conference on Human Factors in Computing Systems, ACM, 1085-1094.

3. Rachel Botsman. 2015. The Changing Rules of Trust in the Digital Age. Harvard Business Review. Retrieved March 29, 2017 from https://hbr.org/2015/10/the-changing-rules-oftrust-in-the-digital-age.

4. Rachel Botsman and Roo Rogers. 2010. Beyond Zipcar: Collaborative Consumption. Harvard Business Review. Retrieved June 14, 2017 from https://hbr.org/2010/10/beyond-zipcarcollaborative-consumption.

5. Rachel Botsman and Roo Rogers. 2011. What's mine is yours: how collaborative consumption is changing the way we live. Collins, London.

6. Virginia Braun and Victoria Clarke. 2006. Using thematic analysis in psychology. Qualitative Research in Psychology 3, 2: 77-101.

7. Jeffery Bray, Nick Johns, and David Kilburn. 2011. An Exploratory Study into the Factors Impeding Ethical Consumption. Journal of Business Ethics 98, 4: 597-608.

8. Coye Cheshire. 2011. Online Trust, Trustworthiness, or Assurance? Daedalus 140: 49-58.

9. Edward Deci and Richard Ryan. 1985. Intrinsic Motivation and Self-Determination in Human Behavior.

10.Tawanna R. Dillahunt and Amelia R. Malone. 2015. The Promise of the Sharing Economy Among Disadvantaged Communities. Proceedings of the 33rd Annual ACM Conference on Human Factors in Computing Systems, ACM, 2285-2294.
11.Tawanna R. Dillahunt, Xinyi Wang, Earnest Wheeler, Hao Fei Cheng, Brent Hecht, and Haiyi Zhu. 2017. The Sharing Economy in Computing: A Systematic Literature Review. Proc. ACM Hum.-Comput. Interact. 1, CSCW: 38:1-38:26.

12.Dianne Dredge and Szilvia Gyimóthy. 2017. Collaborative Economy and Tourism: Perspectives, Politics, Policies and Prospects. Springer.

13.Koen Frenken and Juliet Schor. Putting the sharing economy into perspective. Environmental Innovation and Societal Transitions. (pp.7-8).

14.Giana M. Eckhardt, Russell Belk, and Timothy M. Devinney. 2010. Why don't consumers consume ethically? - Eckhardt - 2010 - Journal of Consumer Behaviour - Wiley Online Library. Retrieved June 14, 2017 from http://onlinelibrary.wiley.com/doi/10.1002/cb.332/ full.

15. Heo, Cindy Yoonjoung. 2016. Sharing economy and prospects in tourism research. ResearchGate. Retrieved March 22, 2017 from https://www.researchgate.net/publication/295825 703_Sharing_economy_and_prospects_in_touri sm_research.

16.Juho Hamari, Mimmi Sjöklint,Antti Ukkonen. 2015. The Sharing Economy: Why People Participate in Collaborative Consumption. ResearchGate. Retrieved May 30, 2017 from https://www.researchgate.net/publication/255698 095_The_Sharing_Economy_Why_People_Parti cipate_in_Collaborative_Consumption.

17.Siegwart Lindenberg. 2001. Intrinsic Motivation in a New Light. Kyklos 54, 2-3: 317-342.

18.Andrea Prothero, Susan Dobscha, Jim Freund, et al. 2011. Sustainable Consumption: Opportunities for Consumer Research and Public Policy. Social Science Research Network, Rochester, NY.

19.Luhmann, Niklas (2000) 'Familiarity, Confidence, Trust: Problems and Alternatives', in Gambetta, Diego (ed.) Trust: Making and Breaking Cooperative Relations, electronic edition, Department of Sociology, University of Oxford, chapter 6, pp. 94-107. 